\title{
Prenatal Hormone Treatment with Thyrotropin Releasing Hormone and with Thyrotropin Releasing Hormone Plus Dexamethasone Delays Antioxidant Enzyme Maturation but Does Not Inhibit a Protective Antioxidant Enzyme Response to Hyperoxia in Newborn Rat Lung
}

\author{
MARIA P. RODRIGUEZ, ILENE R. S. SOSENKO, MARIA C. ANTIGUA, AND LEE FRANK \\ Divisions of Neonatology and Pulmonary Research, Departments of Pediatrics and Medicine, University of \\ Miami School of Medicine, Miami, Florida 33101
}

\begin{abstract}
Whereas glucocorticoid administration to pregnant rats produces parallel acceleration of lung surfactant and antioxidant enzyme system maturation in late gestation, prenatal thyroid hormone treatment results in acceleration of surfactant maturation, with a paradoxical decrease in antioxidant enzyme (AOE) development. In these studies, we tested whether prenatal thyroid releasing hormone (TRH) treatment would act like prenatal thyroid hormone on pulmonary surfactant and AOE system maturation and whether combined prenatal treatment with TRH plus dexamethasone (DEX) would alter these effects. Secondly, we tested whether prenatal TRH and prenatal TRH plus DEX would inhibit the ability of newborn rats to respond to hyperoxia with protective increases in $\mathrm{AOE}$ activities. Results of the developmental studies revealed significantly increased fetal lung disaturated phosphatidylcholine content with significantly decreased pulmonary AOE activities as a result of prenatal TRH treatment that was not reversed with the addition of DEX. Combined TRH plus DEX treatment resulted in statistically significant decreases in body weight, lung weight, and lung weight to body weight ratios at both 21 and $22 \mathrm{~d}$ of gestation; growth effects were not seen with TRH alone. In terms of hyperoxic AOE response, despite being born with lower baseline AOE levels, the newborn animals prenatally treated with TRH or TRH plus DEX were able to induce a normal pulmonary AOE response to high $\mathrm{O}_{2}$ exposure. Although requiring further investigation, this reassuring finding suggests that clinical prenatal therapy with TRH or the combination of TRH plus DEX is not contraindicated for those infants delivered prematurely who go on to require intensive hyperoxic therapy. (Pediatr Res 30: 522-527, 1991)
\end{abstract}

\section{Abbreviations}

TRH, thyrotropin releasing hormone

$T_{3}, 3,3^{\prime}, 5$-triiodo-L-thyronine

$\mathrm{T}_{4}$, thyroxine

DEX, dexamethasone

AOE, antioxidant enzyme

SOD, superoxide dismutase

CAT, catalase

Received April 25, 1991; accepted May 8, 1991.

Reprint requests: Maria P. Rodriguez, M.D., Dept. of Pediatrics (R-131), University of Miami School of Medicine, P.O. Box 016960, Miami, FL 33101.
GP, glutathione peroxidase

DSPC, disaturated phosphatidylcholine

TPL, total phospholipid

At birth, the newborn lung is exposed to several-fold higher oxygen tension than during its intrauterine development. To prepare for this transition from the in utero to the extrauterine milieu and for its assumption of respiratory function, the developing lung increases both its surfactant content and its $\mathrm{AOE}$ levels during the final 10 to $15 \%$ of gestation (1). The maturation of both of these lung biochemical systems may be crucial in the neonatal adaptation to independent respiration. Cell survival requires that the cell has adequate constitutive antioxidant defense mechanisms and that it has the capacity to rapidly respond to oxidant stress by an increase in the activity of those defense systems that can detoxify reactive species of $\mathrm{O}_{2}$ and thereby prevent $\mathrm{O}_{2}$ toxicity. CAT, SOD, and the enzymes of the glutathione redox cycle (GP, glutathione reductase, and glucose 6phosphate dehydrogenase) are the primary enzymatic intracellular antioxidant defense mechanisms that function together to detoxify the cytotoxic species-superoxide radical, $\mathrm{H}_{2} \mathrm{O}_{2}$, and lipid hydroperoxides (2).

It has been demonstrated recently that in at least five speciesthe rat, rabbit, guinea pig, hamster, and sheep-the development of the surfactant system and the pulmonary AOE system share a chronologically similar late gestational pattern of development (3-6). Experimental evidence also suggests that these two biochemical systems, in addition to their parallel developmental patterns, may share some of the same hormonal regulators as well. We have previously demonstrated that the administration of DEX to pregnant rats in late gestation produced acceleration in both surfactant and AOE system development in their fetal offspring (7). However, whereas the administration of $\mathrm{T}_{3}$ to pregnant rats in late gestation produced acceleration in fetal lung surfactant development, the $T_{3}$ effect on the AOE system development was opposite to that seen for surfactant, with fetal offspring demonstrating delayed pulmonary AOE system development (8).

Thyroid gland production of $T_{4}$ and $T_{3}$ is controlled by the pituitary hormone thyroid stimulating hormone. Thyroid stimulating hormone, in turn, is controlled by the hypothalamic tripeptide TRH (L-pyroglutamyl-L-histidyl-L-prolyl amide), which is also a potent prolactin releasing factor (9). TRH is an 
attractive effector of lung maturation because it readily passes from the maternal to the fetal blood stream and causes thyroid axis stimulation $(10,11)$. Prenatal administration of TRH to pregnant rabbits has been shown to result in increased pulmonary surfactant production as judged by fetal lung lavage surfactant content (10). Prenatal TRH has also been shown to improve lung compliance in ventilated preterm rabbits (12). Based on the information available on TRH, we hypothesized that TRH would act like $T_{3}$ treatment on the developing surfactant and AOE system in the late gestation fetal rat lung.

To further evaluate the hormonal regulation of these two important lung systems, we undertook a series of experimental studies to examine the effects of prenatal TRH treatment alone and TRH in combination with prenatal DEX treatment. The studies were designed to determine l) whether prenatal TRH administration in the rat acts like $\mathrm{T}_{3}$ to accelerate surfactant maturation but depress the maturation of the AOE system;2) whether the combined use of prenatal DEX plus TRH would alter the effects of TRH treatment alone on surfactant and AOE system maturation; and 3) in addition to the effects on $\mathrm{AOE}$ and surfactant system development, whether prenatal treatment with TRH or TRH plus DEX would alter the ability of the newborn offspring to mount a protective AOE response during hyperoxic exposure.

\section{MATERIALS AND METHODS}

The study was conducted in two parts. Part 1 addressed the development of the AOE and surfactant systems after prenatal administration of TRH alone or the combined therapy of TRH plus DEX. Part 2 addressed the response of the AOE and surfactant systems to $5 \mathrm{~d}$ of hyperoxia after prenatal hormone treatment.

Developmental Studies-Part 1. Animals and treatment. Adult Sprague-Dawley albino female rats $(\sim 250 \mathrm{~g})$ were bred by placing male and female animals together overnight, checking for spermpositive vaginal smears the following morning, and considering the midpoint of the cohabitation period as the onset of pregnancy. The timed-pregnant rats were maintained on standard laboratory food and water ad libitum and kept on a 12-h light/ dark cycle.

At $48 \mathrm{~h}$ before premature delivery at $21 \mathrm{~d}$ or full-term delivery at $22 \mathrm{~d}$ gestation, rats were divided into control or treatment groups. For studies examining TRH (Bachem Inc., Torrance, CA) treatment alone, prenatal TRH was administered as a loading dose of TRH s.c. $(25 \mu \mathrm{g} / \mathrm{kg})$ at $48 \mathrm{~h}$ before delivery and by s.c. implantation of an Alzet osmotic minipump (Alza Corp., Palo Alto, CA) through which continuous TRH was administered $(100 \mu \mathrm{g} / \mathrm{kg} / \mathrm{d})$. These doses were chosen based on previous works of Rooney et al. (10) and Ikegami et al. (12). The control groups received an equivolume s.c. injection of saline, as well as a "sham" operation under similar anesthesia. For the studies involving prenatal TRH plus DEX combination therapy, TRH was administered as described above; prenatal DEX was administered at 48 and $24 \mathrm{~h}$ before delivery at a dose of $0.4 \mathrm{mg} / \mathrm{kg}$ intraperitoneally. The control groups received an equivolume dose $(0.5 \mathrm{~mL} / 100 \mathrm{~g})$ of intraperitoneal saline.

At $48 \mathrm{~h}$ after initiation of prenatal hormone treatment, rat fetuses of gestational age 21 or $22 \mathrm{~d}$ were delivered by hysterotomy under ketamine:xylazine anesthesia $(90 \mathrm{mg} / \mathrm{kg}: 10 \mathrm{mg} / \mathrm{kg}$ ) (Ketalar, Parke-Davis, Morris Plains, NJ and Rompun, Paynet Division-Cutter Labs, Shawnee, KS). All of the animal treatment procedures were preapproved by the University of Miami Committee on Research Animal Welfare.

Lung Biochemistry. Fetuses or newborn pups were killed by an intraperitoneal injection of sodium pentobarbitol followed by exsanguination by severing the great vessels in the abdomen. Their lungs were perfused immediately in situ via the pulmonary artery, using iced saline. The left atrial appendage was cut to facilitate drainage of the perfusate. The perfused lungs were then removed, stripped of nonpulmonary tissue, weighed, and homogenized in 20-30 times their weight in cold saline in a polytron (Brinkmann Instruments Co., Westbury, NY) (high speed, $90 \mathrm{~s}$ ). Two to four lungs were pooled per sample so that adequate lung tissue would be provided for the assays. No differentiation between male and female fetuses was made.

Aliquots of the lung homogenate were analyzed for $\mathrm{AOE}$ activities using standard spectrophotometric assays for SOD, CAT, and GP. The SOD assay measures the rate of reduction of cytochrome $C$ at $550 \mathrm{~nm}$, in the presence of $10^{-5} \mathrm{M}$ cyanide (to inhibit cytochrome oxidase activity). Both cytosolic $\mathrm{Cu}-\mathrm{Zn}$ SOD and mitochondrial Mn-SOD are measured by this method (13). CAT, present in the cytosol and peroxisomes of cells, was measured by the rate of reduction of $\mathrm{H}_{2} \mathrm{O}_{2}$ substrate at $240 \mathrm{~nm}$ (14). GP activity was assayed spectrophotometrically at $340 \mathrm{~nm}$ by following the rate of oxidation of NADPH. The assay mixture for measurement of this cytosolic enzyme includes cumene hydroperoxide as primary substrate, with sodium azide added to inhibit contributing activity from CAT enzyme (15). Purified enzyme standards for these assays were obtained from Sigma Chemical Co. (St. Louis, MO) and from Boehringer-Mannheim Biochemicals (Indianapolis, IN).

Aliquots of the lung homogenate were also analyzed for DNA and protein content $(16,17)$, using purified standards from Sigma Chemical Co. Results of the AOE assays were expressed as units of enzyme activity per mg of DNA (and although not reported, were also calculated per mg protein and per $g$ lung wet wt).

For phospholipid analysis, lipid extraction of lung homogenate aliquots was performed according to the procedure of Bligh and Dyer (18), and the lipid extract, once dried under nitrogen, was then frozen at $-70^{\circ} \mathrm{C}$ before phospholipid analysis (18). An aliquot of lipid extract was designated for measurement of TPL. A second aliquot was used for quantitating DSPC, using the method of Mason et al. (19). After separation of the DSPC from the other phospholipids, both the DSPC sample and the TPL sample were analyzed for inorganic phosphorus as described by Morrison (20). A known quantity of ${ }^{14} \mathrm{C}$-dipalmitoyl-phosphatidylcholine (New England Nuclear, Boston, MA) was added before lipid extraction, and aliquots were counted at each step to correct for sequential losses. Lipids were expressed as mg per $\mathrm{g}$ lung wet wt (and also calculated per $\mathrm{mg}$ of protein and as the ratio of $\mathrm{mg}$ DSPC to $\mathrm{mg}$ TPL).

Serum Hormone Assays. From randomly selected TRHtreated or control dams, hormone assays for serum $\mathrm{T}_{3}, \mathrm{~T}_{4}$, and prolactin were done using specific RIA kits (Cambridge Medical Diagnostic, Billerica, MA). Pooled fetal serum (approximately one litter/sample) from randomly selected TRH-treated or control dams was collected for similar hormonal assays.

Hyperoxia Studies-Part 2. Animals and treatment. At $48 \mathrm{~h}$ before spontaneous delivery of full-term offspring, pregnant rats were randomly assigned to either a control (saline) group, TRH treatment group or the combined TRH plus DEX treatment group.

After prenatal hormonal treatment (dosages and treatment regimens as described above for the developmental studies), rat newborns were obtained after normal parturition within $6-12 \mathrm{~h}$ of the beginning of delivery of the first pup. The newborn pups of several equivalently treated litters were first mixed and the redistributed to the equivalently treated, newly delivered dams. Dams plus litters (10-12 pups) were then divided into either hyperoxia exposure or air exposure groups. Exposures were conducted in 3.5-cubic foot clear plastic exposure chambers. The $\mathrm{O}_{2}$ and $\mathrm{CO}_{2}$ levels in the chamber were monitored continuously with Beckman model OM-11 and LB-2 gas analyzers (Beckman Instruments, Inc., Schiller Park, IL). The $\mathrm{O}_{2}$ concentration was maintained at $96-98 \%$, and the $\mathrm{CO}_{2}$ concentration was less than $0.4 \%$ throughout the exposure period. The temperature in the chambers was $24-26^{\circ} \mathrm{C}$ and the humidity was $50-70 \%$ (inchamber thermometers/hygrometers). Animals were fed Ralston-Purina (St. Louis, MO) pellet diet and given water ad 
libitum. The mothers were interchanged daily between litters exposed to $\mathrm{O}_{2}$ and room air to avoid $\mathrm{O}_{2}$ intoxication in the nursing dams. The chambers were opened daily $(10-15 \mathrm{~min})$ to check on the survival, to exchange air and $\mathrm{O}_{2}$ dams, and to provide fresh food, water, and cages. All of the procedures were approved by the University of Miami Committee on Research Animal Welfare.

Lung Biochemistry. After $5 \mathrm{~d}$ of hyperoxia or room air exposure, the pups were killed and their lungs perfused, removed, and homogenized as described for part 1 . Aliquots of the lung homogenate were analyzed for AOE activities, DNA and protein content, and phospholipid and DSPC analysis as described in part 1.

Statistical Analysis. For each assay, multivariate analysis was used to assess the significance of difference between the control and the treatment groups. A large number of variables were calculated and, therefore, the required level for statistical significance was set at different values depending upon the experiment. Using the Bonferroni multiple comparison method, the level for statistical significance was determined to be $p<0.006$ for those experiments that required TRH plus DEX and $p<0.004$ for those experiments that required TRH only (21). The $t$ test was used for the hormone assays, with the level of statistical significance at $p<0.05$. Statistical consultation was obtained from the University of Miami Biostatistics Department.

\section{RESULTS}

Developmental Studies-Part 1. General features of prenatal TRH-treated, TRH plus DEX-treated, and control offspring. Physical characteristics of control and hormone-treated offspring at gestational $\mathrm{d} 21$ and 22 are summarized in Table 1 . At 21 and $22 \mathrm{~d}$ of gestation, the TRH-treated offspring demonstrated statistically significant decreases in body weight and lung weight, with no significant change in lung weight to body weight ratio. Combined TRH plus DEX treatment resulted in statistically significant decreases in body weight, lung weight, and lung weight to body weight ratios at both 21 and $22 \mathrm{~d}$ of gestation.

Serum hormone assays. The $\mathrm{T}_{3}, \mathrm{~T}_{4}$, and prolactin serum levels in TRH-treated versus control dams are shown in Table 2. Prenatal TRH treatment resulted in statistically significant increases in $T_{3}$ and $T_{4}$ serum levels with a significant decrease in prolactin serum levels. (Attempts at hormonal analysis of pooled fetal serum yielded values below the assay limits for $T_{3}, T_{4}$, and prolactin for both hormone-treated and control fetuses.)

Table 1. Physical characteristics of TRH only, TRH + DEX, and control offspring*

\begin{tabular}{|c|c|c|c|}
\hline & Body wt $(\mathrm{g})$ & Lung wt $(\mathrm{g})$ & $\begin{array}{c}\mathrm{LW} / \mathrm{BW} \\
(\%)\end{array}$ \\
\hline \multicolumn{4}{|c|}{ TRH treatment alone } \\
\hline \multicolumn{4}{|l|}{21 d gestation } \\
\hline TRH & $3.65 \pm 0.18 \dagger$ & $0.121 \pm 0.086 \dagger$ & $3.33 \pm 0.16$ \\
\hline Control & $4.01 \pm 0.17$ & $0.148 \pm 0.019$ & $3.70 \pm 0.55$ \\
\hline \multicolumn{4}{|l|}{$22 \mathrm{~d}$ gestation } \\
\hline TRH & $5.76 \pm 0.20 \dagger$ & $0.121 \pm 0.001 \dagger$ & $1.93 \pm 0.13$ \\
\hline Control & $6.52 \pm 0.63$ & $0.143 \pm 0.025$ & $2.18 \pm 0.19$ \\
\hline \multicolumn{4}{|c|}{$\mathrm{TRH}+\mathrm{DEX}$ treatment } \\
\hline \multicolumn{4}{|c|}{21 d gestation } \\
\hline TRH/DEX & $4.01 \pm 0.57 \dagger$ & $0.106 \pm 0.016 \dagger$ & $2.30 \pm 0.23 \dagger$ \\
\hline Control & $4.99 \pm 0.51$ & $0.132 \pm 0.015$ & $2.95 \pm 0.25$ \\
\hline \multicolumn{4}{|l|}{$22 \mathrm{~d}$ gestation } \\
\hline TRH/DEX & $4.52 \pm 0.31 \dagger$ & $0.077 \pm 0.186 \dagger$ & $1.71 \pm 0.43 \dagger$ \\
\hline Control & $5.58 \pm 0.71$ & $0.108 \pm 0.100$ & $2.19 \pm 0.49$ \\
\hline
\end{tabular}

*Values are means \pm 1 SD for six to 13 litters/group/gestational age. $\mathrm{LW} / \mathrm{BW}$, lung wt to body wt ratio.

† Statistically significant with a $p<0.006$ for the litters treated with TRH plus DEX compared with controls (saline-treated) and a $p<0.004$ for the litters treated with TRH alone compared with control litters.
Table 2. Serum $T_{3}, T_{4}$, and prolactin levels in $T R H$-treated and control dams*

\begin{tabular}{lccc}
\hline & $\mathrm{T}_{3}(\mathrm{nmol} / \mathrm{L})$ & \multicolumn{1}{c}{$\mathrm{T}_{4}(\mathrm{nmol} / \mathrm{L})$} & $\begin{array}{c}\text { Prolactin } \\
(\mu \mathrm{g} / \mathrm{L})\end{array}$ \\
\hline TRH treated & $0.849 \pm 0.227 \dagger$ & $14.80 \pm 4.76 \dagger$ & $4.52 \pm 1.01 \dagger$ \\
Control & $0.410 \pm 0.172$ & $10.81 \pm 4.50$ & $5.56 \pm 0.89$ \\
\hline
\end{tabular}

$*$ Values are means \pm 1 SD for 15 dams in each group.

$\uparrow$ Statistically significant with a $p<0.05$ for the TRH-treated compared with control dams.

Table 3. Lung tissue DSPC and TPL content in TRH-treated, $T R H+D E X$-treated, and control offspring*

\begin{tabular}{llc}
\hline & DSPC & TPL \\
\hline TRH treatment alone & & \\
21 d gestation & & \\
TRH & $3.27 \pm 0.21 \dagger$ & $15.8 \pm 1.2$ \\
Control & $2.76 \pm 0.10$ & $15.0 \pm 0.9$ \\
22 d gestation & & \\
TRH & $5.64 \pm 1.29 \dagger$ & $24.5 \pm 8.8 \dagger$ \\
$\quad$ Control & $3.62 \pm 0.82$ & $16.9 \pm 3.4$ \\
TRH + DEX treatment & & \\
21 d gestation & & \\
TRH/DEX & $4.49 \pm 1.36 \dagger$ & $14.8 \pm 4.9$ \\
$\quad$ Control & $3.42 \pm 0.85$ & $15.3 \pm 4.9$ \\
22 d gestation & & \\
TRH/DEX & $5.16 \pm 1.19 \dagger$ & $23.0 \pm 6.1$ \\
Control & $4.02 \pm 0.93$ & $22.0 \pm 5.9$ \\
\hline
\end{tabular}

* Values are means \pm 1 SD for six to 13 litters/group/gestational age. DSPC and TPL are expressed as $\mathrm{mg} / \mathrm{g}$ lung.

$\dagger$ Statistically significant with a $p<0.006$ for the litters treated with TRH + DEX and a $p<0.004$ for the litters treated with TRH alone compared with control litters.

Lung biochemistry. The developmental pattern of lung tissue surfactant (DSPC) and TPL content (expressed as $\mathrm{mg} / \mathrm{g}$ lung) in TRH-treated and TRH plus DEX-treated versus control offspring at gestational d 21 and 22 are shown in Table 3. Offspring of TRH-treated dams had statistically significant increases in lung tissue DSPC content compared with control values at 21 and $22 \mathrm{~d}$ of gestation. Similarly, offspring of TRH plus DEXtreated dams had significantly increased mean lung tissue DSPC content compared with controls at both gestational days studied (The same relationship held true when DSPC and TPL content were expressed per mg of protein rather than per $g$ wet wt of the lung). There was no effect on protein, DNA, or protein/DNA ratios in the hormonally treated offspring.

The comparative late gestational development of the pulmonary AOE system in the three experimental groups is illustrated in Figure 1. At $21 \mathrm{~d}$ of gestation, the TRH-treated offspring demonstrated statistically significant decreases in pulmonary SOD (40\%), CAT (20\%), and GP (35\%) enzyme activities compared with control group values, and at $22 \mathrm{~d}$ gestation had statistically significant decreases in SOD (47\%) and CAT (18\%) activities with a decrease in GP (16\%) activity that approached significance when compared with controls. The addition of DEX treatment to prenatal TRH treatment did not reverse the inhibitory effect of TRH on lung AOE system development, but instead produced significantly depressed levels at gestational d 21 and 22 for each AOE studied, with CAT (38\% decrease d 22) and GP (41\% decrease $d 22$ ) levels even further depressed than with TRH treatment alone.

Hyperoxia Studies-Part 2. Lung biochemistry. After hyperoxic exposure, TRH-treated offspring showed a statistically significant increase in the lung tissue surfactant (DSPC) and TPL content (expressed as mg/g lung), which increased 24 and $21 \%$, respectively (versus increases of 18 and $6 \%$, respectively, in controls). In TRH plus DEX offspring, after hypoxic exposure there were statistically significant increases in DSPC and TPL 

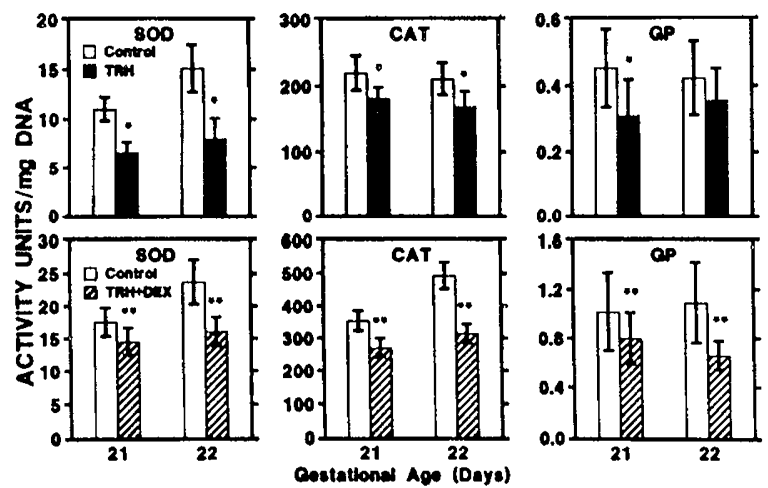

Fig. 1. Effect of prenatal hormonal treatment on lung AOE system development. Values are mean \pm 1 SD for six to 13 litters per group per gestational age. AOE activity levels are calculated per mg DNA. *, Statistically significant with a $p<0.004$ for the litters treated with TRH alone compared with controls (saline-treated); ${ }^{* *}$, statistically significant with a $p<0.006$ for the litters treated with TRH plus DEX compared with control litters.
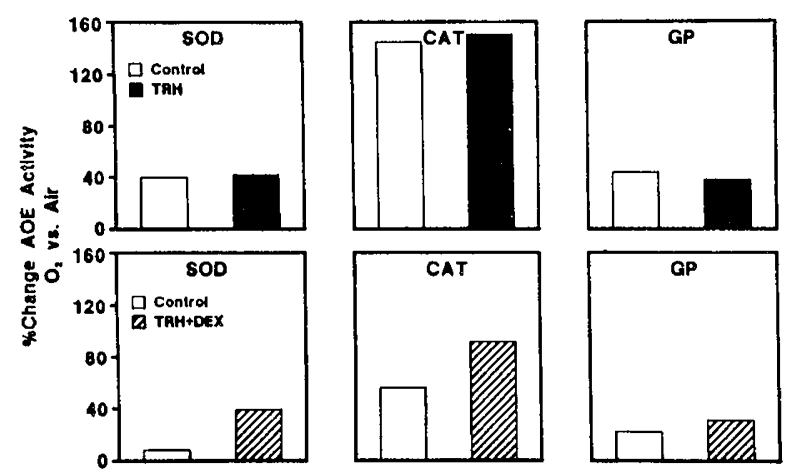

Fig. 2. Comparative AOE responses to hyperoxia $\left(>95 \% \mathrm{O}_{2}\right.$ for $\left.5 \mathrm{~d}\right)$ in hormonally treated and control offspring. Values are $\%$ change in activity for $\mathrm{AOE}$ in $\mathrm{O}_{2}$ exposed rat lungs compared with air-exposed lung AOE values ( $n=$ eight to 12 litters per group). AOE activity levels of aircontrols for TRH experiments: SOD $9.07 \pm 3.79$; CAT $294 \pm 45$; and GP $0.23 \pm 0.63$ units/mg DNA. AOE activity levels of air control for TRH + DEX experiments: SOD $6.31 \pm 2.43$; CAT $181 \pm 36$; and GP $0.27 \pm 0.02$ units/mg DNA. All $\mathrm{O}_{2}$ values are significantly increased compared with respective air controls. Percentage of change in $\mathrm{AOE}$ activities are similar in hormonally treated $v s$ control pups in $\mathrm{O}_{2}$.

content, which increased 44 and $36 \%$, respectively (versus increases of 13 and $11 \%$, respectively, in controls). The same relationships held true when DSPC and TPL were expressed per $\mathrm{mg}$ of protein rather than per $\mathrm{g}$ wet wt of lung.

The activity changes of the pulmonary AOE after $5 \mathrm{~d}$ of hyperoxia (expressed as \% change compared with room airexposed activity levels) are shown in Figure 2. Despite lower AOE levels at the time of birth (Fig. 1), the newborn animals prenatally treated with either TRH alone or TRH plus DEX were able to induce an adaptive AOE response to hyperoxic exposure of similar or even greater magnitude compared with control $\mathrm{O}_{2}$-exposed offspring.

\section{DISCUSSION}

The late gestational time course of maturation of the surfactant system and the pulmonary AOE system is similar in all tested animal species (22). The development of these two critical lung biochemical systems has been shown to be not only chronologically related, but also related by some similar hormonal control mechanisms; i.e. prenatal DEX therapy has been found to accelerate both fetal lung surfactant system and AOE system maturation, whereas prenatal metyrapone (an inhibitor of endogenous glucocorticoid synthesis) treatment causes significantly delayed development of both lung systems (23). In terms of thyroid hormones, however, unlike their role in promoting surfactant system maturation (24-29), prenatal $T_{3}$ treatment has been found to significantly depress the normal maturation of the fetal lung AOE system (8). These in vivo findings are consistent with in vitro studies by other investigators that demonstrated a trend toward decreases in CAT and GP activities in fetal lung cell cultures after the addition of $T_{3}$ to the serum-free medium. The in vitro results suggest that $T_{3}$ is acting directly on the lung and not via systemic actions or via other serum factors (30). The presence of high-affinity binding sites for thyroid hormone in nuclei of fetal lung cells also suggests that the fetal lung is a direct target tissue for thyroid hormone interaction (31).

The mechanism of the depression by $\mathrm{T}_{3}$ of the normal late gestational rise in AOE activity is not yet known, i.e. whether the findings represent decreased enzyme synthesis, increased enzyme degradation, or inactivation of AOE without direct effects on synthesis or degradation per se (32). Based on the work of Floros et al. (33) and Nichols et al. (34, 35), who reported decreases in surfactant-associated proteins A, B, and C mRNA in rat lung after $T_{3}$ treatment (which still enhanced the synthesis of surfactant phospholipid), we would speculate that TRH treatment (via $\mathrm{T}_{3}$ ) may similarly be decreasing gene transcription for the AOE and, ultimately, AOE synthesis (36).

Because neither $T_{3}$ nor $T_{4}$ crosses the human placenta in significant amounts, two approaches seem feasible to provide the human fetus with the potential benefits of thyroid hormone to stimulate surfactant system maturation in threatened premature delivery. One approach is by intraamniotic instillation of $T_{3}$ and $\mathrm{T}_{4}$. Experimentally, direct in utero administration of thyroxine to fetal rabbits results in enhanced lung maturation as judged by lung lavage surfactant content and morphometric studies (3739 ). The second approach, stimulating endogenous fetal production of $\mathrm{T}_{3}$ and $\mathrm{T}_{4}$ by maternal treatment with TRH (which does cross the placenta), is the approach that is currently being tested clinically. This recent clinical interest in testing the efficacy of prenatal TRH treatment in turn stimulated us to investigate the effects of TRH on both fetal lung biochemical development and newborn lung adaptation to hyperoxia.

In the present study, we investigated in part 1 whether prenatal TRH treatment would act like $\mathrm{T}_{3}$ on the developing surfactant and AOE systems; we found substantial increases in lung DSPC in late gestation TRH-treated fetuses, as well as significant decreases in CAT, SOD, and GP activities, similar to those found previously with $T_{3}$ treatment (8). In addition, to determine whether DEX (which accelerates AOE development) would be able to reverse the effect of TRH (depression of AOE development), we used combined drug therapy and found that although the addition of DEX to TRH resulted in a greater positive effect on surfactant system maturation (increased DSPC), combined DEX plus TRH treatment produced an enhanced negative effect on AOE system development, with further depression of CAT and GP activities in the late gestation fetal lung. This apparent inability of DEX to counteract TRH's depression of AOE system development might be explained if these two hormones act on different cell types or if both TRH and DEX act on the type II pneumocyte (the alveolar lining cell most resistant to hyperoxic exposure) $(29,40-42)$ but at different sites. It appears from the hormonal measurements in the present study that TRH is working through the secretion of $T_{3}$ and $T_{4}$ rather than through the release of prolactin, which is consistent with studies previously reported by Klindt et al. (43) in fetal lambs as well as the human studies most recently reported by Ballard et al. (44).

Hyperoxia studies have consistently revealed that the ability to rapidly increase lung AOE activity during an $\mathrm{O}_{2}$ challenge correlates with the resistance of the animal to the toxic effects of $\mathrm{O}_{2}$ on the lung $(41,45,46)$. Newborn rats demonstrate this adaptive lung biochemical response and are markedly tolerant to hyperoxic exposure, whereas adult rats are deficient in their 
lung $\mathrm{AOE}$ responsiveness (showing no $\mathrm{AOE}$ increases during $>95 \% \mathrm{O}_{2}$ exposure) and are much more susceptible to the toxic consequences of high $\mathrm{O}_{2}$ exposure. Thus, the ability to respond rapidly to hyperoxic challenge with an increase over the basal levels of enzyme activity appears to be the most important factor in protection of the lung from $\mathrm{O}_{2}$ free radical injury $(47,48)$. In line with this concept, in part 2 of our studies, we were able to demonstrate that despite lower AOE levels at the time of birth prenatally treated newborns (TRH plus DEX or TRH alone) were able to mount a normal protective $\mathrm{AOE}$ response to hyperoxia, with AOE activity increases of similar magnitude as in the control newborns. All of the neonatal animals were alive after 5 $\mathrm{d}$ in $>95 \% \mathrm{O}_{2}$. Thus, even though both hormonal treatments produced (worrisome) depressions of baseline protective AOE levels in the newborns, neither TRH alone nor TRH plus DEX pretreatment impaired the newborn lung's capacity to manifest an appropriate biochemical protective response to postnatal high $\mathrm{O}_{2}$ challenge.

The incidence of respiratory distress syndrome in prematurely born infants has been reduced with the use of prenatal glucocorticoid therapy $(49,50)$. However, the clinical benefits of glucocorticoids are limited by the number of pregnancies in which steroids have been shown to be ineffective $(51,52)$. Because of these limiting factors on the clinical efficacy of glucocorticoid treatment, trials of TRH and TRH plus glucocorticoid prenatal therapy have recently been instituted $(53,54)$. The findings from part 1 of our investigations, which showed significant depression of normal AOE system development with TRH alone or with combined TRH plus DEX treatment, might have raised serious concerns about the clinical use of these agents in prematurely delivered infants who went on to require hyperoxic therapy. However, the results from part 2 of our study have effectively eased these concerns, inasmuch as no detrimental effect on the ability of the newborn animal lung to respond appropriately to hyperoxia was observed after antenatal TRH or TRH plus DEX treatment. The findings in our animal study are somewhat in agreement with the human collaborative studies of Ballard et al. (54); although we report substantial increases in lung surfactant content after prenatal hormone therapy, they saw no reduction in the incidence of respiratory distress syndrome. Although there are no studies that definitively demonstrate that $\mathrm{AOE}$ regulation is identical in humans and animals, our finding of an enhanced ability to mount a protective AOE response to hyperoxic exposure may correspond to the decreased incidence of chronic lung disease in the studies of Ballard et al. (54).

Identification of new agents or drugs that can regulate the normal development of the AOE system or augment these protective enzymes may provide a means to allow for the safer use of high oxygen therapy in neonatal intensive care units.

\section{REFERENCES}

1. Frank L, Massaro D 1980 Oxygen toxicity. Am J Med 69:117-126

2. Huber GL, Drath DB 1981 Pulmonary oxygen toxicity. In: Gilbert DL (ed) Oxygen and Living Processes: An Interdisciplinary Approach. Springer Verlag, New York, pp 273-342

3. Frank L, Sosenko IRS 1987 Prenatal development of lung antioxidant enzyme in four species. J Pediatr 110:1066-1110

4. Gerdin R, Tyden O, Erikkson UJ 1985 The development of antioxidant enzyme defenses in the perinatal rat lung: activities of superoxide dismutase, glutathione peroxidase, and catalase. Pediatr Res 19:682-691

5. Tanswell AK. Freeman BA 1984 Pulmonary antioxidant enzyme maturation in fetal and neonatal rat lung. I. Developmental profiles. Pediatr Res 18:584586

6. Walther FJ, Chang M. Wade A. Forman HJ, Warburton B 1989 AOE ontogeny in lamb lung. Pediatr Res 25:63A(abstr)

7. Frank L. Lewis PL. Sosenko IRS 1985 Dexamethasone stimulation of fetal rat lung antioxidant enzyme activity in parallel with surfactant stimulation. Pediatrics 75:569-574

8. Sosenko IRS, Frank L 1987 Thyroid hormone depresses antioxidant enzyme maturation in fetal rat lung. Am J Physiol 253:R592-R598

9. Wilson JD, Foster DW 1985 Textbook of endocrinology. In: Williams RH (ed) Neuroendocrinology. WB Saunders, Philadelphia, pp 510-514

10. Rooney SA. Marino PA, Gobran LI, Gross I. Warshaw JB 1979 Thyrotropin- releasing hormone increases the amount of surfactant in lung lavage from fetal rabbits. Pediatr Res 13:623-625

11. Liggins GC, Schellenberg JC 1986 Hormones and lung maturation. In: Johnston BM, Gluckman PD (eds) Reproductive and Perinatal Medicine. III Respiratory Control and Lung Development in the Fetus and Newborn. Perinatology Press, New York, pp 107-133

12. Ikegami M, Jobe AH, Pettenazzo A, Seidner SR, Berry DD, Ruffini L 1987 Effects of maternal treatment with corticosteroids, $\mathrm{T}_{3}, \mathrm{TRH}$ and their combination on lung function of ventilated preterm rabbits with and without surfactant treatment. Am Rev Respir Dis 136:892-898

13. McCord JM, Fridovich I 1969 Superoxide dismutase: an enzymatic function for erythrocuprein (Hemocuprein). J Biol Chem 244:6049--6055

14. Holmes RS, Masters CJ 1970 Epigenetic interconversions of the multiple forms of mouse liver catalase. FEBS Lett 11:45-48

15. Paglia DE, Valentine WN 1967 Studies on the quantitative and qualitative characterization of erythrocyte glutathione peroxidase. $J$ Lab Clin Med 70:158-159

16. Richards GM 1974 Modification of the diphenylamine reactions giving in creased sensitivity and simplicity in the estimation of DNA. Anal Biochem 57:369-376

17. Schacterle GR. Pollack RL 1973 A simplified method for the quantitative assay of small amounts of protein in biological materials. Anal Biochem 51:654-655

18. Bligh EF, Dyer WJ 1959 A rapid method of total lipid extraction and purification. Can J Biochem Physiol 37:911-917

19. Mason RJ, Nellenbogen J, Clements JA 1976 Isolation of disaturated phosphatidylcholine with osmium tetroxide. J Lipid Res 17:281-284

20. Morrison WR 1964 A fast simple and reliable method for the microdetermi nation of phosphorous in biological materials. Anal Biochem 11:218-224

21. Neter J, Wasserman W 1974 Applied Linear Statistical Models. Richard D. Irwin, Inc., Homewood, IL

22. Frank L, Bucher JR, Roberts RJ 1978 Oxygen toxicity in neonatal and adult animals of various species. J Appl Physiol 45:699-704

23. Sosenko IRS, Lewis PL, Frank L 1986 Metyrapone delays surfactant and antioxidant enzyme maturation in developing rat lung. Pediatr Res 20:672675

24. Cunningham MD, Hollingsworth DR, Belin RP 1980 Impaired surfactant production in cretin lambs. J Obstet Gynecol 55:439-443

25. Erenberg A, Rhodes ML. Weinstein MM, Kennedy RL 1979 The effect of thyroidectomy on ovine fetal lung maturation. Pediatr Res 13:230-235

26. Smith BT, Torday JS 1974 Factors affecting lecithin synthesis by fetal lung cells in culture. Pediatr Res 8:848-851

27. Hitchcock KR 1979 Hormones and the lung. I. Thyroid hormone and glucocorticoids in lung development. Anat Rec 194:15-39

28. Gross I, Dynia DW, Wilson CM, Inglesin LD, Gewolb IH, Rooney SA 1984 Glucocorticoid-thyroid hormone interaction in fetal rat lung. Pediatr Res 18:191-196

29. Smith BT, Sabry K 1983 Glucocorticoid-thyroid synergism in lung maturation: a mechanism involving epithelial-mesenchymal interaction. Proc Natl Acad Sci USA 80:1951-1954

30. Tanswell AK. Tzaki MG. Byrne PJ 1986 Hormonal and local factors influence antioxidant enzyme activity of fetal lung cells in vitro. Exp Lung Res 11:4959

31. Lindenberg JA, Brehier A, Ballard PL 1978 Triiodothyronine nuclear binding in fetal and adult rabbit lung and cultured lung cells. Endocrinology 103:1725-1731

32. Sosenko IRS, Frank L 1989 Thyroid inhibition and developmental increases in fetal lung antioxidant enzymes. Am J Physiol 257:L194-L199

33. Floros J, Phelp DS, Smith BT 1985 Two dimensional gel electrophoresis of dexamethasone induced organ specific development proteins (fsa, fsb) in rat lung fibroblast. Electrophoresis 6:238-241

34. Nichols KV. Dynia DW, Floros J, Veletza SV, Lequillo R, Gross I 1989 Hormonal regulation of fetal rat surfactant proteins A and B mRNA. A comparison. Pediatr Res 25:57 A(abstr)

35. Nichols KV, Floros J, Dynia DW, Veletza SV, Wilson CM, Gross I 1990 Regulation of surfactant protein A mRNA by hormones and butyrate in cultured fetal lung. Am J Physiol 259:L488-L495

36. Gross I 1990 Regulation of fetal lung maturation. Am J Physiol 259:L337L344

37. Wu B, Kikkawa Y, Orzalesi MM, Motoyama EK, Kaibora M, Zigas CJ, Cook CD 1973 The effect of thyroxine on the maturation of fetal rabbit lungs. Biol Neonate 22:161-168

38. Mashiach S, Barkai G, Sack J, Stern E, Brish M, Goldman B, Serr DM 1979 The effect of intraamniotic thyroxine administration on fetal lung maturity in man. $\mathrm{J}$ Perinatol 7:16I-170

39. Morishige WK. Guernsy DL 1978 Triiodothyronine receptors in rat lung. Endocrinology 102:1628-1632

40. Balentine JD 1977 Experimental pathology of oxygen toxicity. In: Jobsis FF (ed) Oxygen and Physiological Function. Professional Information Library, Dallas, TX, pp 311-378

41. Evans MJ. Hackney JD 1972 Cell proliferation in lung of mice exposed to elevated concentrations of $\mathrm{O}_{2}$. Aerosp Med 43:620-625

42. Kistler GS, Caldwell PRB, Weibel ER 1967 Development of fine structural damage to alveolar and capillary lining cells in oxygen-poisoned rat lungs. $J$ Cell Biol 32:605-627

43. Klindt J, Davis SL, Ohlson DL 1979 Plasma concentration of thyrotropinreleasing hormone, thyrotropin, prolactin, and growth hormone during five- 
day osmotic pump infusion of thyrotropin-releasing hormone. Endocrinology 104:45-49

44. Ballard PL, Ballard RA, Creasy R, Gross I, Moya FR, Padbury JF 199 Thyroid hormone and prolactin levels in premature infants exposed to thyrotropin releasing hormone (TRH) in utero. Pediatr Res 29:307A(abstr)

45. Frank L, Autor AP, Roberts RJ 1977 Oxygen therapy and hyaline membrane disease: the effect of hyperoxia on pulmonary superoxide dismutase activity and the mediating role of plasma or serum. J Pediatr 90:105-110

46. Frank L, Wood DL, Roberts RJ 1978 Effect of diethyldithiocarbamate on oxygen toxicity in immature and adult rats. Biochem Pharmacol 27:251254

47. Yam J, Frank L, Roberts RJ 1978 Oxygen toxicity: comparison of lung biochemical responses in neonatal and adult rats. Pediatr Res 12:115-119

48. Frank L, Sosenko IRS 1991 Failure of premature rabbits to increase antioxidant enzymes during hyperoxic exposure: increased susceptibility to pulmonary oxygen toxicity compared with term rabbits. Pediatr Res 29:292-296
49. Collaborative Group on Antenatal Steroid Therapy 1981 Effect of antenatal dexamethasone administration on the prevention of respiratory distress syndrome. Am J Obstet Gynecol 141:276-286

50. Doran TA, Swyer P, MacMurray B 1980 Results of a double-blind controlled study on the use of betamethasone in the prevention of respiratory distress syndrome. Am J Obstet Gynecol 136:313-320

51. Gross I 1979 The hormonal regulation of fetal lung maturation. Clin Perinatol $6: 377-395$

52. Ballard PL, Ballard RA, Granberg JP, Sniderman S, Gluckman PD, Koplan SL, Grumback MM 1980 Fetal sex and prenatal betamethasone therapy. Pediatr 97:451-454

53. Morales WJ, O'Brien WF, Angel JL, Knuppel RA, Sawai S 1989 Fetal lung maturation: the combined use of corticosteroids and thyrotropin-releasing hormone. Obstet Gynecol 73:111-115

54. Ballard RA, Ballard PL, Creasy R, Gross I, Padbury JF 1991 Prenatal thyrotropin releasing hormone plus corticosteroid decreases chronic lung disease in very low birth weight infants. Pediatr Res 29:307A(abstr) 